\title{
Involvement of a Second Lymphoid-Specific Enhancer Element in the Regulation of Immunoglobulin Heavy-Chain Gene Expression
}

\author{
TOWIA ARON LIBERMANN, MICHAEL LENARDO,† AND DAVID BALTIMORE* \\ Whitehead Institute for Biomedical Research, Cambridge, Massachusetts 02142, and Department of Biology, \\ Massachusetts Institute of Technology, Cambridge, Massachusetts 02139
}

Received 13 December 1989/Accepted 8 March 1990

\begin{abstract}
To determine whether enhancer elements in addition to the highly conserved octamer (OCTA)-nucleotide motif are important for lymphoid-specific expression of the immunoglobulin heavy-chain (IgH) gene, we have investigated the effect of mutating the binding site for a putative additional lymphoid-specific transcription factor, designated NF- $\mu \mathrm{B}$, in the murine IgH enhancer. We demonstrate that the NF- $\mu$ B-binding site plays a critical role in the IgH enhancer, because mutation of the $\mu$ B DNA motif decreased transcriptional activity of the IgH enhancer in cells of the B-cell lineage but not in nonlymphoid cells. This effect was comparable to or even stronger than the effect of a mutation in the OCTA site. Moreover, combined mutation of both $\mu B$ and OCTA sites further reduced enhancer activity in lymphoid cells. Interestingly, alteration of either the $\mu B$ or E3 site in a 70-base-pair fragment of the IgH enhancer that lacks the binding site for OCTA abolished enhancer activity in lymphoid cells completely. Nevertheless, a multimer of the $\mu \mathrm{B}$ motif alone showed no enhancer activity. DNase footprinting analysis corroborated the functional data showing that a lymphoid-specific protein binds to the $\mu B$ DNA motif. Our results suggest that the $\mu B$ element is a new crucial element important for lymphoid-specific expression of the IgH gene but that interaction with another enhancer element is essential for its activity.
\end{abstract}

The 700-base-pair (bp)-long immunoglobulin heavy-chain (IgH) enhancer shows a complex modular structure of a variety of overlapping positive-acting enhancer elements and negative-acting elements (for a review, see reference 35 ). The majority of these elements appear to bind ubiquitous transcription factors that are present in both lymphoid and nonlymphoid cells $(2,8,16,28,31,32,34,35)$. The $E$ boxes E1, E2, E3, and E4 represent one group of such enhancer elements $(6,8,16,23)$. Mutational studies have suggested that the E-box elements contribute to the transcriptional regulation of the IgH gene but do not determine lymphoid specificity $(13,16,27,42)$. An additional enhancer element, $\mathrm{E}$, has been identified by binding of a protein designated $\mu$-EBP (42). Deletion analysis has provided evidence for functional importance of this element (42). Negative elements present in the enhancer appear to be active only in nonlymphoid cells and thus might contribute to lymphoidspecific expression of the $\operatorname{IgH}$ enhancer $(30,44)$.

Only one enhancer element thus far characterized, a highly conserved octamer (OCTA)-nucleotide motif, ATTT GCAT, has been shown to confer some lymphoid specificity to the IgH gene (for a review, see reference 35). OCTA binds a variety of ubiquitous and cell-restricted factors $(17,33,39)$. The Oct-1 transcription factor is ubiquitously expressed in all cell types $(15,39,41)$, whereas Oct- 2 expression is restricted to $B$ cells, some $\mathrm{T}$ cells, and some glial cells (14, $15,38,39)$. The OCTA-nucleotide sequence is present in both the IgH promoter and enhancer $(3,9,19,25,36)$ and has been found in a variety of other genes $(4,5,18,20,26,37)$. Nevertheless, mutation of the OCTA sequence in the context of the whole IgH enhancer has only very little effect on its activity in lymphoid cells $(16,27)$, suggesting the presence

\footnotetext{
* Corresponding author.

† Present address: Laboratory of Immunology, National Institute of Allergy and Infectious Diseases, Bethesda, MD 20892.
}

of additional lymphoid-specific enhancer elements. Indeed, a 460-bp fragment of the IgH enhancer that lacks the OCTA sequence retains substantial lymphoid-specific enhancer activity (16; this paper).

Araki et al. (1) have recently shown that introduction of nuclear extracts from myeloma cells into murine L cells containing the human IgH gene leads to specific expression of the IgH gene. However, depletion of OCTA-nucleotidebinding factors from myeloma nuclear extracts did not diminish induction of $\mathrm{IgH}$ gene expression in $\mathrm{L}$ cells (1). They identified a new nuclear factor that showed characteristics of a second lymphoid-specific transcription factor. This factor has been purified from a murine myeloma and binds to the sequence 5'-TATTTTAGGAAGCAAA- 3 ' in the human IgH enhancer just downstream of the E3 motif (1). The murine IgH enhancer contains a similar but not identical sequence at the same location (Fig. 1). The purified factor has been shown to induce expression in the human IgH gene in murine $\mathrm{L}$ cells and thus may play a critical role in $\mathrm{IgH}$ gene expression (1).

To determine the functional role of this new factor, designated NF- $\mu \mathrm{B}$ in this study, we have introduced mutations into the homologous NF- $\mu \mathrm{B}$ - and OCTA-binding sites of the murine IgH enhancer. We tested whether the murine $\mathrm{IgH}$ enhancer $\mu \mathrm{B}$ element is functionally comparable to the human $\operatorname{IgH}$ enhancer element and whether the $\mu \mathrm{B}$ motif could be responsible for the lymphoid-specific expression of an OCTA-deleted IgH enhancer. We have found that mutation of $\mu \mathrm{B}$ reduces activity of the murine $\mathrm{IgH}$ enhancer in pre-B, mature B, and plasma cells but not in NIH 3T3 fibroblasts. We have narrowed down the lymphoid-specific element to a 70-bp fragment that contains $\mu \mathrm{B}$ and E3 but not OCTA. In contrast to other enhancer elements, no intrinsic enhancer activity was detected with the $\mu \mathrm{B}$ motif by itself, suggesting a necessity for interaction with another enhancer element. Our results suggest that $\mu \mathrm{B}$ together with OCTA 


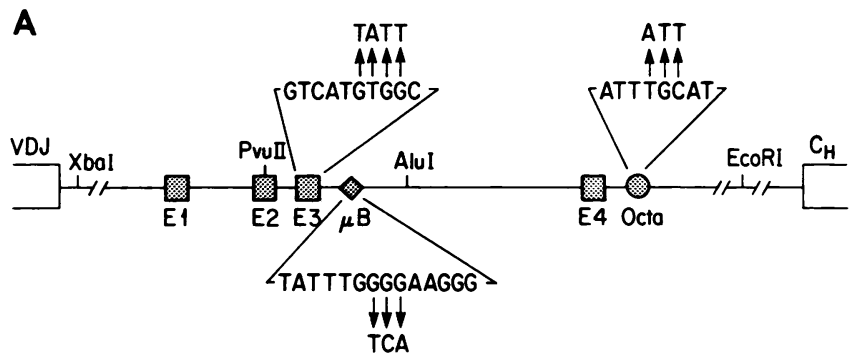

B

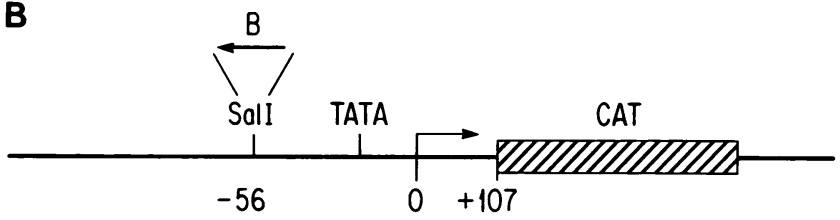

FIG. 1. Structures of IgH enhancer constructs used for transfections. (A) Schematic diagram of mutations introduced into the murine IgH enhancer. Filled symbols represent the various transcription factor-binding sites. The circle indicates the OCTA motif; boxes show the different E-box sites; the diamond indicates the $\mu \mathrm{B}$ DNA motif. The wild-type sequences of E3, $\mu \mathrm{B}$, and OCTA are indicated by the expansions above and below the diagram. Arrows point to the nucleotides introduced by mutations into the wild-type sequence. Open boxes represent exons for the constant and variable regions; the thin line indicates the intron. The enhancer fragment referred to as $\mu 700$ extends between the $X b a I$ and $E c o$ RI sites. $\mu 300$ extends between the $P v u I I$ and $E c o R I$ sites. The segment referred to as $\mu 460$ extends between the $X b a I$ and $A l u I$ sites, and fragment $\mu 70$ extends between the PvuII and AluI sites. (B) The insertion site (Sall) for enhancer fragments into the c-fos promoter $\triangle 56 / C A T$ fusion plasmid 56 bp upstream of the transcription start site. The B orientation is the reverse orientation of the enhancer fragments shown in panel $\mathrm{A}$.

may determine most of the lymphoid-specific expression of the IgH gene and demonstrate that the $\mu \mathrm{B}$ DNA motif binds a lymphoid-specific factor or factors.

\section{MATERIALS AND METHODS}

Cell culture. S194 (murine myeloma), NIH 3T3 (murine fibroblast), HeLa (human cervical carcinoma), U-Cl2:6 (human glioma), and EJ (human bladder carcinoma) cells were grown in Dulbecco modified Eagle medium containing $10 \%$ fetal calf serum. PD31 (murine Abelson murine leukemia virus-transformed pre-B cell line) and BJAB (human B-cell lymphoma) cells were maintained in RPMI 1640 supplemented with $10 \%$ fetal calf serum and $50 \mu \mathrm{M} 2$-mercaptoethanol. HAFTL (murine Harvey v-ras-transformed early preB-cell line) cells were grown in RPMI 1640 medium containing $15 \%$ fetal calf serum and $50 \mu \mathrm{M} 2$-mercaptoethanol. 32D (murine early myeloid cell line) cells were grown in RPMI 1640 supplemented with $5 \%$ fetal calf serum and $10 \%$ conditioned medium from WEHI 3 cells.

Nuclear extracts. Nuclear extracts were prepared according to the method of Dignam et al. (7). Nuclear extract from 32D cells was kindly provided by Stephen Smale (Whitehead Institute). Heparin-agarose fractions of nuclear extracts from HeLa and BJAB cells were kindly provided by Mark Kamps (Whitehead Institute).

Enhancer/chloramphenicol acetyltransferase (CAT) plasmid construction. The XhoI-linkered 700-bp IgH enhancer and fragments thereof were inserted into the SalI site in the $\triangle$-56-c-fos-CAT plasmid described by Gilman et al. (10) and Lenardo et al. (16) in the B orientation (Fig. 1B).
A synthetic 34-bp $\mu$ B oligonucleotide

5'-TCGAGCAAGGCTATTTGGGGAAGGGAAAATAAAG-3 $3^{\prime}$ - CGTTCCGATAAACCCCTTCCCTTTTATTTCAGCT-5'

containing SalI and $\mathrm{XhoI}$ ends was inserted as a monomer, dimer, and tetramer into the SalI site in the $\triangle 56$-c-fos-CAT plasmid $(10,16)$.

Site-directed mutagenesis. Plasmids containing mutations in either OCTA or E3 were derived from plasmids described by Lenardo et al. (16). Specific site-directed mutagenesis of three nucleotides in the $\mu \mathrm{B}$ DNA motif of the murine IgH enhancer between positions 414 and 427 was introduced by the gapped/heteroduplex method (40), using an oligonucleotide 5'-GTGGCAAGGCTATTTGTCAAAGGGAAAATAA3' (Fig. 1A).

DNA transfection assays. Transfections of cells were carried out with $10 \mu \mathrm{g}$ of $\mathrm{IgH}$ enhancer/ $\triangle 56$ plasmid, using the DEAE-dextran method $(16,29)$. NIH 3 T3 cells were transfected by the calcium phosphate coprecipitation method (16, 29). The cells were harvested $48 \mathrm{~h}$ after transfection, and 30 to $100 \mu \mathrm{g}$ of heat-inactivated (16) cell extract was assayed for CAT activity as described previously (11) in a 1-h incubation at $37^{\circ} \mathrm{C}$. Transfections for every construct were performed independently in duplicate and repeated two to four times. Samples were analyzed by thin-layer chromatography (11). The percentage of acetylated chloramphenicol was determined by cutting out nonacetylated and acetylated forms of chloramphenicol and measuring the amount of radioactivity by liquid scintillation counting.

DNase I footprinting analysis. $\mu 460 / \triangle 56$ and $\mu 460 \mu \mathrm{B}^{-} /$ $\triangle 56$ (Fig. 1 and 2) were linearized with HindIII, dephosphorylated, and end labeled with $\left[\gamma^{-32} \mathrm{P}\right] \mathrm{ATP}$ and T4 polynucleotide kinase at the $5^{\prime}$ end of the noncoding strand. After digestion with SalI, end-labeled $\mu 460$ and $\mu 460 \mu B^{-}$ HindIII-SalI fragments were gel purified. DNase I footprinting was performed as described by Jones et al. (12), using 0.3 to $0.8 \mathrm{ng}$ of end-labeled IgH enhancer fragments $(5,000 \mathrm{cpm})$, $20 \mu \mathrm{g}$ of total nuclear extract, $3 \mu \mathrm{g}$ of heparin-agarosepurified nuclear extract, or no protein, $1 \mu \mathrm{g}$ of poly(dI-dC) for total nuclear extract and $0.2 \mu \mathrm{g}$ for heparin-agarose fractions, and $2 \%$ polyvinyl alcohol in $50 \mu \mathrm{l}$. A ladder of G+A Maxam-Gilbert (21) sequence reaction of the labeled $\mathrm{IgH}$ enhancer fragments was run as a marker.

\section{RESULTS}

Lymphoid-specific transcription of the IgH enhancer is for the most part dependent on two enhancer elements, OCTA and $\mu \mathrm{B}$. The $\mu \mathrm{B}$ site (Fig. 1A) was identified as a putative lymphoid-specific enhancer element (1) along with the OCTA motif (16). To study these enhancer elements, we introduced mutations in the $\mu \mathrm{B}$, OCTA and E3 sites by using synthetic oligonucleotides (Fig. 1A). Wild-type and mutant IgH enhancers as well as fragments thereof (Fig. 2) were cloned into the SalI site just upstream of the truncated c-fos promoter of the $\triangle 56$ plasmid $(10,16)$ in the $B$ orientation (Fig. 1B). We measured enhancer activity as the ability of the different enhancer constructs to induce transcription of the CAT gene after transient expression in a variety of cell types. The full-length 700-bp IgH enhancer ( $\mu 700$ WT) stimulated transcription 50-fold in S194 myeloma cells and 20 -fold in PD31 pre-B lymphoid cells (Fig. 2, line 1) relative to the level of the control plasmid (Fig. 2, line 14). The transcriptional activities of mutant enhancers were compared with the level of either the full-length or partial fragments of the wild-type 700-bp IgH enhancer ( $\mu 700 \mathrm{WT})$ 


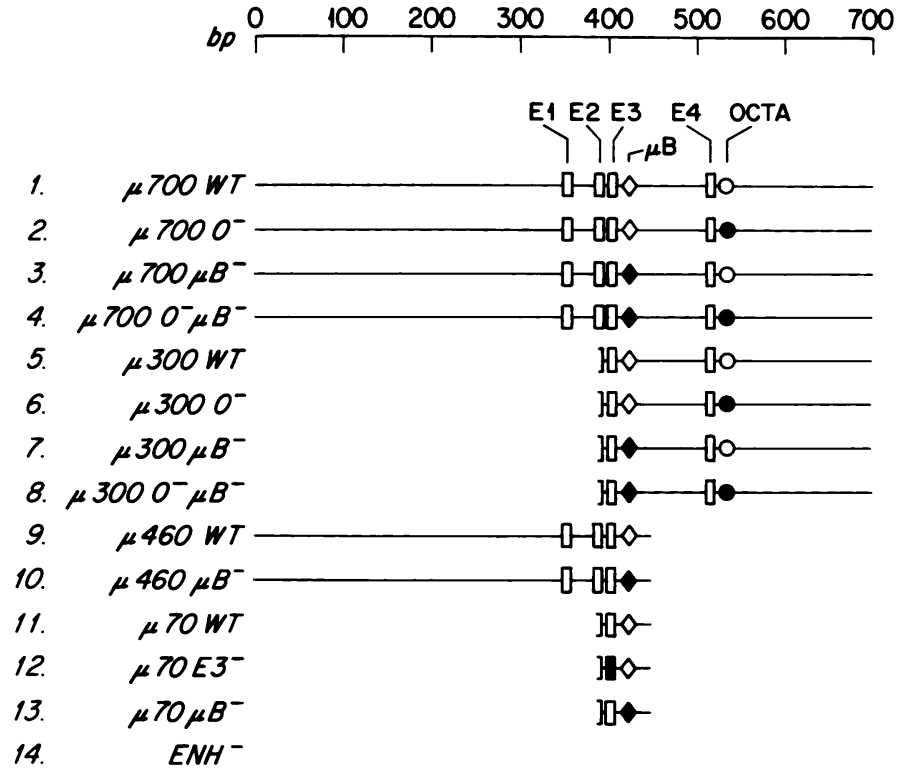

\begin{tabular}{r|r}
$\begin{array}{r}\text { \% Relative Cot Activity } \\
\text { S194 }\end{array}$ & PD31 \\
\hline 100 & 100 \\
58 & 89 \\
45 & 44 \\
15 & 25 \\
841 & 318 \\
515 & 139 \\
396 & 30 \\
145 & 11 \\
13.5 & n.d. \\
2.0 & n.d. \\
10.5 & n.d. \\
1.9 & n.d. \\
1.8 & n.d. \\
2.0 & 5.0
\end{tabular}

FIG. 2. Relative activities of IgH enhancer fragments and mutations in S194 myeloma and PD31 pre-B cells. Symbols indicate the positions of the different enhancer elements, analogous to those in Fig. 1A. Empty symbols represent wild-type configurations; solid boxes indicate mutated sites as depicted in Fig. 1A. Deletions are given by the loss of part of the thin line. Half of a box indicates deletion starting in the middle of the E2 site. The CAT activity of each construct transfected into either S194 or PD31 cells is compared with that of the wild-type $\mu 700 \mathrm{IgH}$ enhancer/CAT construct in line 1. CAT values are averages derived from one representative experiment of two independent transfections. Repeated experiments gave similar results, with deviations of less than $20 \%$ compared with the values given. ENH ${ }^{-}$(line 14 ) indicates the enhancerless $\triangle 56$ background plasmid.

(Fig. 2 to 4). The $3^{\prime} 300$-bp part of the IgH enhancer $(\mu 300$ WT), which lacks E1 and E2, expressed 8.4- and 3.2times-higher CAT activity than did $\mu 700 \mathrm{WT}$ in S194 and PD31 cells, respectively (Fig. 2, line 5). However, in the A orientation (16), $\mu 700$ expressed much higher activity than did $\mu 300$ (data not shown).

Mutation in the OCTA motif within $\mu 700\left(\mu 700 \mathrm{O}^{-}\right)$ reduced CAT activity in S194 myeloma cells by only about $40 \%$ (Fig. 2, line 2; Fig. 3A) but had a very small effect in the pre-B-cell line PD31 (Fig. 2, line 2; Fig. 3B), suggesting the presence of lymphoid-specific enhancer elements in $\mu 700$ independent of OCTA (16). We therefore tested the effect of a mutation in the $\mu B$ DNA motif on enhancer activity. Mutation in the $\mu \mathrm{B}$ motif within $\mu 700\left(\mu 700 \mu \mathrm{B}^{-}\right)$resulted in a decrease of about 55\% in both S194 and PD31 cells (Fig. 2, line 3; Fig. $3 A$ and $B$ ). Interestingly, mutation in the $\mu B$ DNA motif had an even more drastic effect on transcription of $\mu 700$ in a very early pre-B-cell line, HAFTL, in which the $\mu \mathrm{B}^{-}$mutation reduced CAT activity by more than $80 \%$ (Fig. 3C). By contrast, the OCTA mutation had only a slight effect in this cell line (Fig. $3 \mathrm{C}$ ). These results suggest that the $\mu \mathrm{B}$ site encodes an $\mathrm{IgH}$ enhancer element that may be more important for transcriptional activity in cells early in the B-lymphoid lineage. By contrast, OCTA appears to play a larger role in the more mature cells. Strikingly, combined mutation of both the $\mu \mathrm{B}$ and OCTA motifs $\left(\mu 700 \mathrm{O}^{-} \mu \mathrm{B}^{-}\right)$ led to severe decreases in CAT activity in all types of B cells (Fig. 2, line 4; Fig. 3). These effects were more dramatic than either mutation alone, reflecting a requirement for both $\mu \mathrm{B}$ and OCTA. In S194 and PD31 cells, residual enhancer activities of 15 and $25 \%$ of $\mu 700$ WT activity, respectively, were observed even when both $\mu B$ and OCTA sites were mutated. Thus, further enhancer elements present in the $\mathrm{IgH}$ enhancer must be active.

Similar results were obtained when mutating the OCTA or $\mu \mathrm{B}$ motif in the context of the $\mu 300$ enhancer fragment (Fig. 1, from the PvuII to EcoRI sites), which lacks E1, E2, and other putative upstream elements (Fig. 2, lines 5 to 8; Fig. 3). As for $\mu 700$, mutations in $\mu \mathrm{B}$ always had a stronger effect on transcription than did mutations in OCTA (Fig. 2, lines 5 to 7; Fig. 3). This was particularly evident in PD31 cells, in which mutation in $\mu \mathrm{B}$ decreased CAT activity by more than 10-fold, whereas mutation in OCTA led to only a 2-fold decrease (Fig. 3B). Double mutation in both $\mu B$ and OCTA within $\mu 300$, similar to $\mu 700$, caused greater decreases in transcription than either alone in S194, PD31, and HAFTL cells (Fig. 2, line 8; Fig. 3).

To assess the functional consequence of the removal of the whole $3^{\prime}$ end of the enhancer, containing both E4 and OCTA, we created $\mu 460$ (Fig. 2, lines 9 and 10). This deletion led to a drastic reduction of transcription to $13.5 \%$ of the level of $\mu 700 \mathrm{WT}$ in S194 cells, suggesting that important sites other than OCTA are removed by this deletion (Fig. 2, line 9). Alterations in the $\mu \mathrm{B}$ motif within this construct abrogated all enhancer activity in S194 cells (Fig. 2, lines 9 and 10). Thus, even though $\mu 460$ contains several E-box elements (E1, E2, and E3), mutation of $\mu B$ alone drastically reduces the transcriptional activity of $\mu 460$. This context illustrates most vividly the importance of the $\mu B$ site for the IgH enhancer.

$\mu B$ needs a second enhancer element for its function. Because alteration of the $\mu \mathrm{B}$ site in $\mu 460$ suggested that this site might be the crucial enhancer element in this fragment, we made further truncations of the IgH enhancer. $\mu 70 \mathrm{WT}$, containing only the E3 and $\mu \mathrm{B}$ motifs as identified enhancer elements but lacking E1, E2, E4, and OCTA, expressed transcriptional activity similar to that of $\mu 460$ in S194 cells (Fig. 2, lines 9 and 11). Mutation of either the E3 or $\mu B$ site abolished enhancer activity of $\mu 70$ in S194 cells (Fig. 2, lines 11 to 14). Because alteration of E3 had the same effect as 

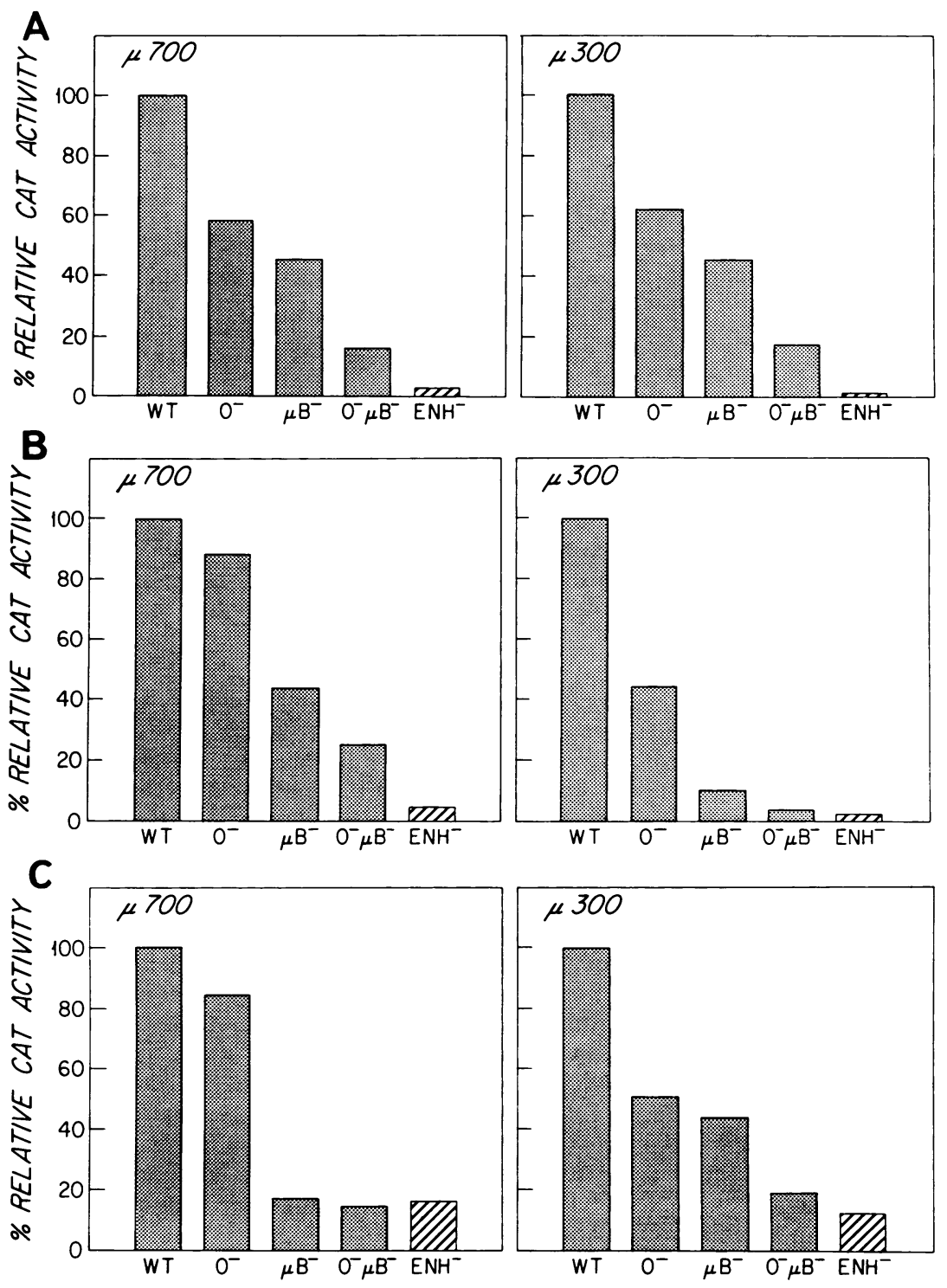

FIG. 3. Effects of mutations on IgH enhancer transcription rate. The $\mu 700$ and $\mu 300 \mathrm{IgH}$ enhancers with mutations in either $\left.\mathrm{OCTA}^{-} \mathrm{O}^{-}\right)$ or $\mu \mathrm{B}\left(\mu \mathrm{B}^{-}\right)$were tested in S194 myeloma (A), PD31 pre-B (B), and HAFTL early pre-B (C) cells. In each experiment, each value is the average of two representative independent transfections; repeated experiments gave similar results in which the standard deviations were less than $20 \%$ compared with the values given. Absolute percent conversions of chloramphenicol to acetylated forms were as follows: $\mu 700 \mathrm{WT}$, $7.6 \%$ for S194, $4.4 \%$ for PD31, and $1.8 \%$ for HAFTL; $\mu 300$ WT, $63.8 \%$ for S194, $14 \%$ for PD31, and 2.4\% for HAFTL (the CAT assays with $\mu 300$ were repeated for $\mathrm{S} 194$ cells with less cell extract in order to keep a linear range of chloramphenicol substrate conversion, resulting in conversion of $29.4 \%$ for $\mu 300 \mathrm{WT}$ ); and $\mathrm{ENH}^{-}, 0.15 \%$ for $\mathrm{S} 194,0.22 \%$ for PD31, and $0.26 \%$ for HAFTL. Activity is given as percent relative CAT activity of the wild-type IgH enhancer fragment. Hatched columns represent the parental enhancerless plasmid; dotted columns represent plasmids containing various versions of the enhancer.

mutating $\mu \mathrm{B}$ in this fragment, the simplest explanation is that $\mu B$ does not function by itself but requires a second enhancer element such as E3. To test this possibility, we constructed a synthetic 34-bp oligonucleotide containing the $\mu \mathrm{B}$ motif and its flanking region but lacking E3. We inserted one, two, or four copies of this oligonucleotide into the $\triangle 56$ plasmid. In contrast to the $\mu 70$ fragment, no enhancer activity, even with four copies of the $\mu \mathrm{B}$ oligonucleotide, was detected in S194, PD31, or HAFTL cells (data not shown). Thus, it appears that the $\mu \mathrm{B}$ element does not function independently as an enhancer but needs interaction with another enhancer element for activity.

$\mu B$ and OCTA are not functional in fibroblasts. To test whether $\mu \mathrm{B}$ is functional in nonlymphoid cells, we trans- fected the various constructs into NIH 3T3 fibroblasts. All constructs derived from the $\mu 700$ enhancer as well as the $\mu 70$ constructs were inactive in NIH 3T3 cells. $\mu 300$ WT expressed low but reproducible enhancer activity (Fig. 4). Mutation of the OCTA or $\mu \mathrm{B}$ site or a combination of both within $\mu 300$ resulted in a two- to threefold increase in CAT activity in NIH 3T3 cells (Fig. 4). We have not further investigated the apparent inhibitory effects of these motifs in fibroblasts, but it is evident that the activation effects of the motifs are manifest specifically in B cells but not fibroblasts.

A lymphoid-specific protein binds to the $\mu B$ DNA motif. To correlate the functional data described above with binding of a potential lymphoid-specific protein to the $\mu \mathrm{B}$ motif, we performed DNase I footprinting experiments using the $\mu 460$ 


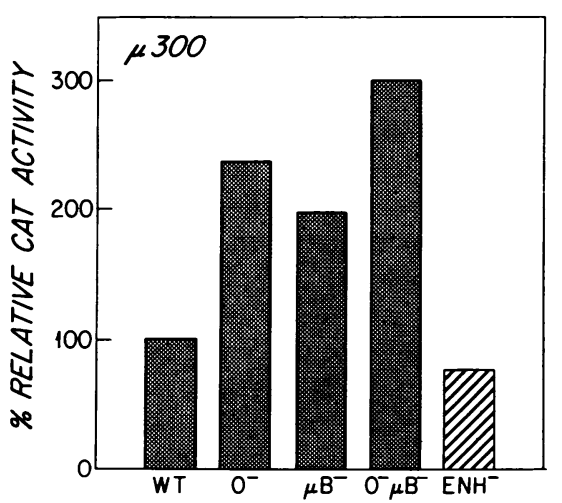

FIG. 4. Effects of mutation in the $\mu \mathrm{B}$ motif within the $\mu 300 \mathrm{IgH}$ enhancer on transcription in fibroblasts. The $\mu 300 \mathrm{IgH}$ enhancers were tested in NIH 3T3 fibroblasts. Absolute percent conversions of chloramphenicol to acetylated forms were as follows: $\mu 300 \mathrm{WT}$, $1.1 \%$ and $\mathrm{ENH}^{-}, 0.85 \%$. Other details are as given in the legend to Fig. 3.

fragment of the IgH enhancer. We compared nuclear extracts derived from lymphoid cells with extracts from nonlymphoid cells (Fig. 5 and 6). Proteins bound to E2 and E3 were detected in extracts of both lymphoid (S194 and BJAB) and nonlymphoid (U-Cl2:6, 32D, NIH 3T3, EJ, and HeLa) cells (Fig. 5 and 6A). A strong footprint over the $\mu B$ DNA motif was seen in extracts from the two lymphoid cell lines S194 (murine myeloma) and BJAB (human B-cell lymphoma) (Fig. 5, lanes 5 and 6; Fig. 6A, lane 3). No footprint over the $\mu B$ site was observed with nuclear extracts from $\mathrm{U}-\mathrm{Cl} 2: 6$, a human glioma (Fig. 5, lane 1), NIH 3T3 mouse fibroblasts (Fig. 5, lane 3), EJ human bladder carcinoma cells (Fig. 5, lane 4), and HeLa human cervical carcinoma cells (Fig. 6A, lane 2). The nuclear extract from the 32D myeloid precursor cell line protected a larger region around the $\mu \mathrm{B}$ site and had a unique enhanced band in the upper part of the $\mu \mathrm{B}$ site (Fig. 5, lane 2). Thus, the 32D nuclear factor(s) has properties very different from those of the B-cell factor. Our results confirm that a lymphoid-specific factor or factors in both murine and human cells bind to the $\mu \mathrm{B}$ motif.

Interestingly, we also detected a strong lymphoid-specific footprint between the E2- and E3-binding sites (Fig. 5) which has not been previously observed. This suggests the possibility of additional lymphoid-specific enhancer elements in the IgH enhancer (T. Libermann and D. Baltimore, unpublished results).

To confirm that mutation in $\mu \mathrm{B}$ decreased binding of the lymphoid-specific factor, we carried out DNase I footprinting experiments comparing the wild-type $\mu 460 \mathrm{WT}$ with the mutant $\mu 460 \mu \mathrm{B}^{-}$enhancer. Heparin-agarose fractions of nuclear extracts derived from HeLa and BJAB cells were used for this experiment. Again, only the BJAB B-cell line, not the HeLa carcinoma cell line, extract gave rise to a footprint over the $\mu \mathrm{B}$ site in the wild-type enhancer (Fig. $6 \mathrm{~A})$. The mutant $\mu \mathrm{B}$ site gave a different DNase digestion pattern, but it was clear that no protection was detected over the altered $\mu \mathrm{B}$ site with an extract from BJAB cells (Fig. 6B). A weak footprint that included the mutant $\mu B$ site was created by the HeLa extract, but this has not been further studied (Fig. 6B). These results have been confirmed by gel mobility shift assays (Libermann and Baltimore, unpublished results). Only a wild-type, not a mutant $\mu B$, oligonucleotide forms a specific complex in B cells but not in glioma, epithelial, and fibroblast cells, and only the wild-type oligo-

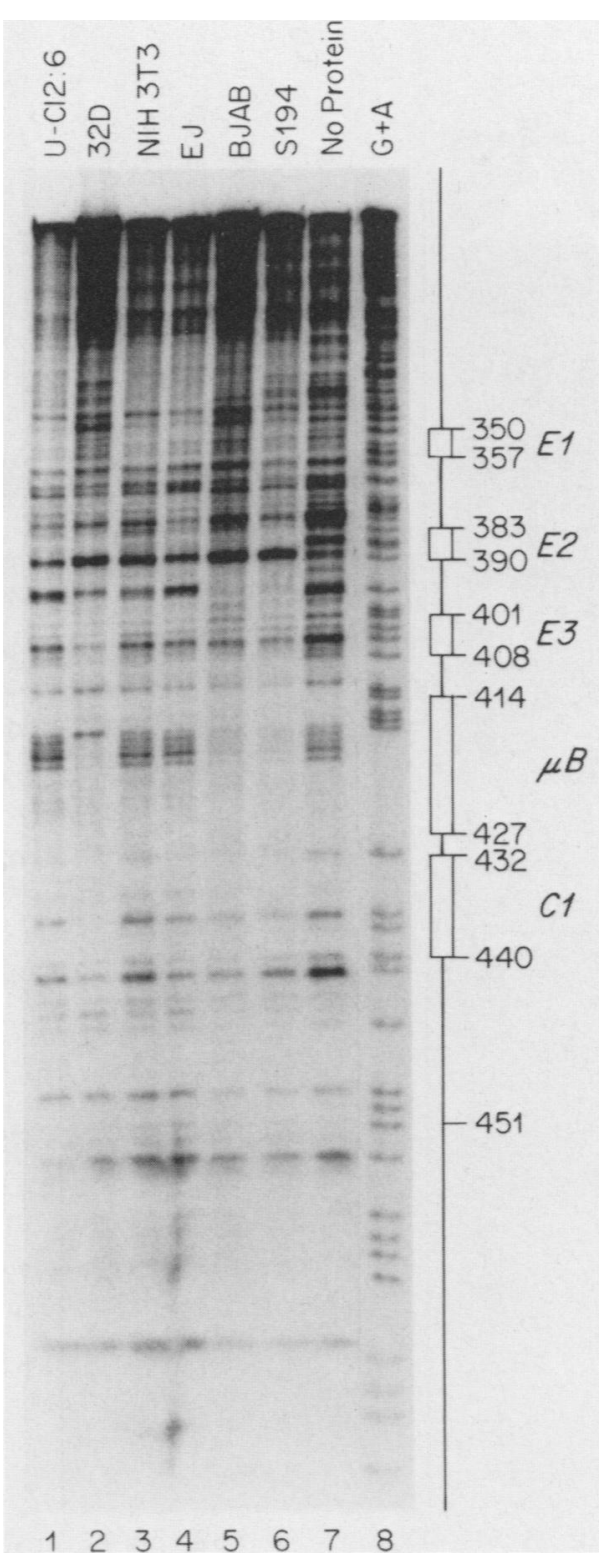

FIG. 5. Detection of IgH enhancer-binding factors by a DNase I footprinting assay using wild-type $\mu 460 \mathrm{IgH}$ enhancer fragment labeled at the $5^{\prime}$ end of the noncoding strand. Labeled $\mu 460$ enhancer fragment was incubated with $20 \mu \mathrm{g}$ of total nuclear extract from U-Cl2:6 glioma cells (lane 1), 32D myeloid precursor cells (lane 2), NIH 3T3 fibroblasts (lane 3), EJ bladder carcinoma cells (lane 4), BJAB B-lymphoid cells (lane 5), and S194 myeloma cells (lane 6). Lane 7 was a control reaction without protein. A G+A MaxamGilbert sequence reaction of the same IgH enhancer fragment was run in lane 8 . The positions and names of the IgH enhancer elements are indicated by the boxes to the right of gel, together with coordinates of each site according to Ephrussi et al. (8).

nucleotide specifically competes with this particular complex (Libermann and Baltimore, unpublished results). Thus, mutation in the $\mu \mathrm{B}$ site indeed decreases affinity for a lymphoid-specific $\mu \mathrm{B}$-binding factor.

\section{DISCUSSION}

We have found that the $\mu \mathrm{B}$ site found just downstream of the $\mathrm{E} 3$ site in the $\mathrm{IgH}$ enhancer is a crucial component of the 


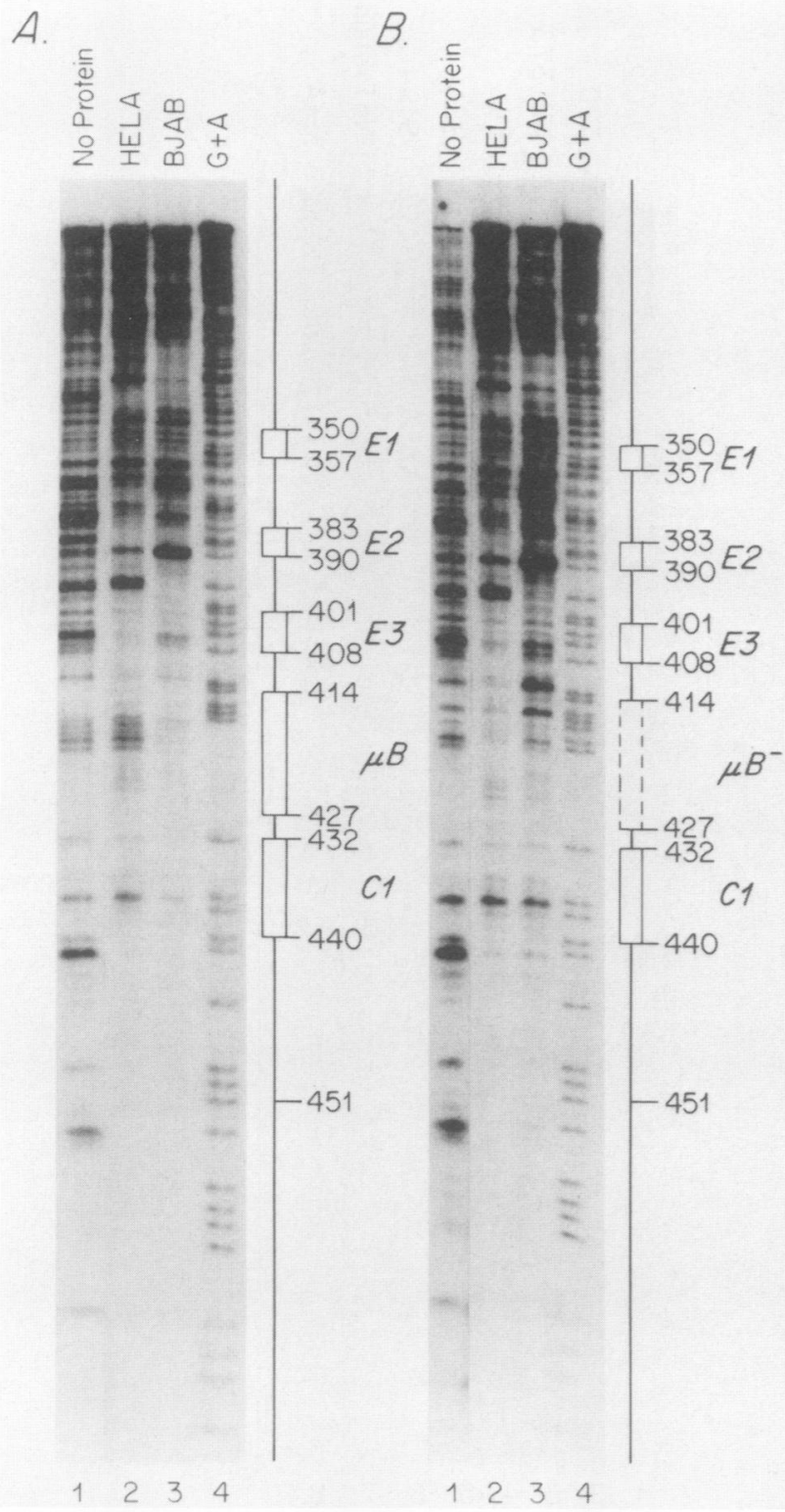

FIG. 6. Binding of nuclear factors to wild-type and mutant $\mu B$ sites in the IgH enhancer in a DNase I footprinting assay using wild-type $\mu 460$ WT (A) and mutant $\mu 460 \mu B^{-}$(B) IgH enhancer fragments labeled and cut as for Fig. 5. Labeled enhancer fragments were incubated with $3 \mu \mathrm{g}$ of heparin-agarose-purified nuclear extract from HeLa (lane 2) or BJAB (lane 3) cells. Lane 1 was a control reaction without protein. $A G+A$ sequence reaction of the same DNA fragments was run as a marker (lane 4). The positions and names of enhancer elements in the IgH enhancer are indicated by solid boxes together with coordinates $(8,16)$ of each site. The box with dashed lines in panel $B$ indicates the position of the altered $\mu B$ site.

IgH gene regulatory region. The $\mu \mathrm{B}$ motif binds a lymphoidspecific nuclear factor, and its alteration substantially reduces IgH enhancer activity in lymphoid cells. In addition, combined mutation of both $\mu \mathrm{B}$ and OCTA sites drastically impairs transcriptional activity of the IgH enhancer. Similar results have been obtained independently by Nelsen et al. (24). It appears that the ability of the IgH enhancer to induce transcription in lymphoid cells but not in nonlymphoid cells is for the most part a consequence of the combined action of two enhancer elements, $\mu \mathrm{B}$ and OCTA. In contrast to OCTA (45), however, the $\mu B$ element by itself does not express enhancer activity but needs interaction with another element to function. Our results indicate that the $\mu \mathrm{B}$ site, together with the OCTA site and probably others, determines the tissue-restricted expression of the IgH gene.

Our purpose in undertaking these studies was to define more completely which enhancer elements contribute to the lymphoid-restricted expression of the IgH gene. The $\mu \mathrm{B}$ motif manifests features of a second lymphoid-specific element in the IgH enhancer. Nevertheless, combined mutation of both the $\mu \mathrm{B}$ and OCTA sites leaves considerable residual enhancer activity that can only be explained by the action of further enhancer elements, possibly the $E$ boxes $(6,8,16,34$, 43). Indeed, preliminary evidence suggests that an mRNA coding for an E-box-binding protein is preferentially expressed in B cells (C. Murre and D. Baltimore, unpublished results).

B-cell specificity of the $\mathrm{IgH}$ gene is apparently regulated by both positive-acting B-cell-specific enhancer elements and negative-acting non-B-lymphoid-specific elements. Indeed, recent evidence suggests that repression of the $\operatorname{IgH}$ enhancer plays a role in silencing of the enhancer in non-B cells $(30,44)$. Two negative elements that flank the 700 -bp IgH enhancer have been identified and might be related to matrix attachment points (30). It is therefore not surprising that a 300 -bp fragment of the IgH enhancer ( $\mu 300)$ is somewhat transcriptionally active in nonlymphoid cells, whereas the whole $\mu 700 \mathrm{IgH}$ enhancer is inactive in nonlymphoid cells (16). An apparent negative element has been located to a region between the $\mu \mathrm{E} 1$ and $\mu \mathrm{E} 2$ enhancer elements (44). This negative element suppresses enhancer activity in non-B cells and is absent in the $\mu 300$ fragment (44). However, even the 300-bp fragment which lacks identified negative elements appears to be a very weak enhancer in NIH 3T3 cells if compared with B cells. Mutation of either the OCTA or $\mu B$ site leads to increased activity of $\mu 300$ in NIH 3T3 cells, suggesting that factors binding to these sites in NIH $3 \mathrm{~T} 3$ cells might repress rather than enhance activity. Another less likely explanation might be that mutation of these sites allows binding of positive factors to the mutated sites that are specific for NIH 3T3 cells. Negative regulation may contribute to lymphoid specificity of the IgH enhancer. However, positive-acting lymphoid-specific elements are essential to explain all aspects of lymphoid-specific IgH enhancer expression.

Mutation in the OCTA site within $\mu 300$ did not lead to as drastic a decrease in transcriptional activity as previously reported (16) but reduced CAT activity by only 50 to $60 \%$ in different B-cell lines. This discrepancy might be due to the use of different cell lines in the previous report. More important, mutation of the $\mu \mathrm{B}$ site in all cell lines revealed a greater decrease in transcription than did mutation in the OCTA site. This difference was independent of the length of IgH enhancer fragment tested. This difference was particularly striking in the pre-B-cell line PD31 and might be due to different amounts of NF- $\mu$ B and Oct-2 protein in PD31 pre-B cells and S194 myeloma cells. PD31 cells might contain relatively more NF- $\mu$ B than S194 cells. Interestingly, in the B orientation $\mu 300$ expressed much higher transcriptional activity than did $\mu 700$, whereas in the A orientation $\mu 700$ was more active than $\mu 300$. This effect might be due to the difference in activity of the various enhancer elements dependent on the distance to the c-fos promoter. In the B orientation but not in the A orientation, E3, $\mu \mathrm{B}$, and OCTA 
are closer to the transcription initiation point in $\mu 300$ than in $\mu 700$.

Using the DNase I footprinting technique, we have demonstrated specific binding of a nuclear factor or factors, termed NF- $\mu \mathrm{B}$, to the $\mu \mathrm{B}$ site of the murine IgH enhancer. $\mathrm{NF}-\mu \mathrm{B}$ seems to be present only in B-lymphoid and some T-lymphoid (unpublished results) cells as well as in macrophage cell lines (unpublished results) of both human and mouse origin but is absent in fibroblasts, epithelial cells, and glial cells. Partial protection of the $\mu \mathrm{B}$ site was also detected in nuclear extracts from the myeloid precursor cell line 32D, even though the footprint pattern over the $\mu B$ site was strikingly different from that created by nuclear extracts from lymphoid cells. This finding suggests the presence of a factor related but not identical to NF- $\mu$ B. Both DNase I footprinting analysis and gel mobility shift experiments (unpublished results) have confirmed that the mutant $\mu \mathrm{B}$ site is unable to bind NF- $\mu \mathrm{B}$.

Unexpectedly, we observed an additional putative lymphoid-specific footprint in the region between the ubiquitously protected E2 and E3 sites, raising the possibility that a third lymphoid-specific enhancer element is present in the IgH enhancer. We have preliminary evidence that this new site is indeed a functional enhancer (Libermann and Baltimore, unpublished results).

Lymphoid-specific protection over the $\mu \mathrm{B}$ site has been previously suggested by the experiments of Ephrussi et al. (8) with in vivo experiments and by Augereau and Chambon (2) with in vitro DNase footprinting. Araki et al. (1) have recently reported the purification of a nuclear protein from a murine myeloma that binds to a site of the human IgH enhancer that is homologous to the murine $\mathrm{IgH}$ enhancer $\mu \mathrm{B}$ site, although the murine $\mu B$ sequence differs in 4 of 16 nucleotides from the human $\mu B$-like site. We now demonstrate that the murine $\mu B$ site has features resembling the human homolog (see also Nelsen et al. [24]). Thus, like the OCTA motif, the $\mu \mathrm{B}$ motif and its factor are important elements of the IgH enhancer that are apparently conserved between species.

Araki et al. (1) showed that their factor is capable of inducing transcription of the human IgH gene when introduced into mouse $\mathrm{L}$ cells containing a transfected rearranged IgH gene. Nuclear extracts from nonlymphoid cell lines were unable to induce high expression of the $\mathrm{IgH}$ gene in $\mathrm{L}$ cells. Our mutational analysis of the $\mu B$ motif in the murine IgH enhancer provides evidence that the murine $\mu \mathrm{B}$ site has features similar to the human homolog. Our results show directly that the $\mu \mathrm{B}$ motif plays a crucial role in $\mathrm{IgH}$ enhancer activity and together with the DNase footprinting experiments support the notion that the $\mu \mathrm{B}$ motif acts as a lymphoid-specific enhancer component. Indeed, the $\mu \mathrm{B}$ motif appears to have a stronger effect on IgH enhancer transcription in pre-B cells than does the OCTA element.

There is an important difference between the function of the OCTA and the $\mu B$ elements. The OCTA motif acts as a lymphoid-specific enhancer independently of other enhancer elements (45), whereas even a tetramer of the $\mu \mathrm{B}$ motif is completely devoid of enhancer activity in a variety of cell lines tested. Nevertheless, transcription of a small 70-bp fragment of the IgH enhancer that contains the E3 and $\mu \mathrm{B}$ sites works as an enhancer element and is dependent on the integrity of the $\mu \mathrm{B}$ site. There are several explanations for the lack of independent enhancer activity of the $\mu B$ element. (i) We might have missed part of the NF- $\mu$ B-binding site when constructing the oligonucleotide. This is unlikely, because our oligonucleotide contains flanking regions on both ends extending well over the putative binding site described by Araki et al. (1) for the human $\mu B$-like element and functionally defined by Nelsen et al. (24). (ii) The $\mu B$ motif is inactive in the context of the c-fos promoter/CAT construct. This is also unlikely, because the $\mu \mathrm{B}$ element acts as an enhancer in this plasmid in the context of other IgH enhancer elements. (iii) The spacing of the $\mu \mathrm{B}$ motifs in the multimers does not allow "productive" NF- $\mu$ B binding to the element. At present we have no evidence against or for this possibility. (iv) Interactions between NF- $\mu$ B and proteins binding to additional enhancer elements are needed for the function of the $\mu \mathrm{B}$ element, or NF- $\mu \mathrm{B}$ binds only after modulation of the $\mu \mathrm{B}$ site by an additional enhancer element. Our results support this explanation, because alteration of either the $\mu \mathrm{B}$ or the $\mathrm{E} 3$ site within the $\mu 70 \mathrm{IgH}$ enhancer fragment abolished most if not all enhancer activity of this fragment. Whether E3 is the only enhancer element that directly interacts with $\mu \mathrm{B}$ we do not yet know. Also, it is not clear whether NF- $\mu \mathrm{B}$ and NF- $\mu \mathrm{E} 3$ can directly interact.

Interestingly, Meyer and Neuberger (22) have recently identified an enhancer $3^{\prime}$ of the immunoglobulin $\kappa$ gene that contains a $\mu$ B-like sequence flanked by an E3-like motif, albeit in orientation inverse to that of the IgH enhancer. The novel immunoglobulin $\kappa$ enhancer they describe also contains a sequence similar to that of the new enhancer element found between E2 and E3 in the IgH enhancer (Libermann and Baltimore, unpublished results). Interactions between different enhancer elements are likely to be important, as shown by the lack of demonstrable activity of $\mu \mathrm{B}$ oligonucleotides. The mechanism by which other enhancer elements and their associated binding proteins modulate the transcriptional effect of the $\mu \mathrm{B}$ motif will be an interesting area for future research.

\section{ACKNOWLEDGMENTS}

We thank Barbara Nelsen, Tom Kadesch, and Ranjan Sen for communicating their results to us prior to publication. We thank Jacqueline Pierce and Stephen Smale for helpful discussions.

This work was supported by a fellowship from the Leukemia Society of America to T.A.L., a National Cancer Institute clinical investigator award to M.L., and Public Health Service grant GM 39458 to D.B. from the National Institutes of Health.

\section{LITERATURE CITED}

1. Araki, K., H. Maeda, J. Wang, D. Kitamura, and T. Watanabe. 1988. Purification of a nuclear trans-acting factor involved in the regulated transcription of a human immunoglobulin heavy chain gene. Cell 53:723-730.

2. Augereau, P., and P. Chambon. 1986. The mouse immunoglobulin heavy-chain enhancer: effect on transcription in vitro and binding of proteins present in HeLa and lymphoid B cell extract. EMBO J. 5:1791-1797.

3. Bergman, Y., D. Rice, R. Grosschedl, and D. Baltimore. 1984. Two regulatory elements for immunoglobulin $\mathrm{k}$ light chain gene expression. Proc. Natl. Acad. Sci. USA 81:7041-7045.

4. Bohmann, D., W. Keller, T. Dale, H. R. Schoeler, G. Tebb, and I. W. Mattaj. 1987. A transcription factor which binds to the enhancers of SV40, immunoglobulin heavy-chain and U2 snRNA genes. Nature (London) 325:268-272.

5. Carbon, P., S. Murgo, J. P. Ebel, A. Krol, G. Tebb, and I. Mattaj. 1987. A common octamer motif binding protein is involved in the transcription of U6 snRNA by RNA polymerase III and U2 snRNA polymerase II. Cell 51:71-79.

6. Church, G. M., A. Ephrussi, W. Gilbert, and S. Tonegawa. 1985. Cell type specific contacts to immunoglobulin enhancers in nuclei. Nature (London) 313:798-801.

7. Dignam, J. P., R. M. Lebovitz, and R. G. Roeder. 1983. Accurate transcription initiation by RNA polymerase II in a 
soluble extract from isolated mammalian nuclei. Nucleic Acids Res. 11:1475-1489.

8. Ephrussi, A., G. M. Church, S. Tonegawa, and W. Gilbert. 1985. B lineage-specific interactions of an immunoglobulin enhancer with cellular factors in vivo. Science 227:134-138.

9. Falkner, F. G., R. Mocikat, and H. G. Zachau. 1986. Sequences closely related to an immunoglobulin gene promoter/enhancer element occur also upstream of other eukaryotic and of prokaryotic genes. Nucleic Acids Res. 14:8819-8827.

10. Gilman, M. Z., R. N. Wilson, and R. A. Weinberg. 1986. Multiple protein-binding sites in the 5 '-flanking region regulate c-fos expression. Mol. Cell. Biol. 6:4305-4316.

11. Gorman, C. M., L. F. Moffat, and B. H. Howard. 1982. Recombinant genomes which express chloramphenicol acetyltransferase in mammalian cells. Mol. Cell. Biol. 2:1044-1051.

12. Jones, K. A., K. R. Yamamoto, and R. Tijan. 1985. Two distinct transcription factors bind to the HSV thymidine kinase promoter in vitro. Cell 42:559-572.

13. Kiledjian, M., L.-K. Su, and T. Kadesch. 1988. Identification and characterization of two functional domains within the murine heavy-chain enhancer. Mol. Cell. Biol. 8:145-152.

14. Ko, H.-S., P. Fost, W. McBride, and L. M. Staudt. 1988. A human protein specific for immunoglobulin octamer DNA motif contains a functional homeobox domain. Cell 55:135-144.

15. Landolfi, N. F., J. D. Capra, and P. W. Tucker. 1987. Proteinnucleotide contacts in the immunoglobulin heavy-chain promoter region. Proc. Natl. Acad. Sci. USA 84:3851-3855.

16. Lenardo, M., J. W. Pierce, and D. Baltimore. 1987. Proteinbinding sites in Ig gene enhancers determine transcriptional activity and inducibility. Science 236:1573-1577.

17. Lenardo, M. J., L. Staudt, P. Robbins, A. Kuang, R. C. Mulligan, and D. Baltimore. 1989. Repression of the IgH enhancer in teratocarcinoma cellls associated with a novel octamer factor. Science 243:544-546.

18. Margin, M., M. Ares, and A. M. Weiner. 1986. Human U2 small nuclear RNA genes contain an upstream enhancer. EMBO J. 5:987-995.

19. Mason, J. O., G. T. Williams, and M. S. Neuberger. 1985. Transcription cell type specificity is conferred by an immunoglobulin $\mathrm{V}_{\mathrm{H}}$ gene promoter that encodes a functional consensus sequence. Cell 41:479-487.

20. Mattaj, I. W., S. Lienhard, J. Jiricny, and E. M. de Robertis. 1985. An enhancer-like sequence within the Xenopus U2 gene promoter facilitates the formation of stable transcription complexes. Nature (London) 316:163-167.

21. Maxam, A. M., and W. Gilbert. 1980. Sequencing end-labeled DNA with base-specific chemical cleavages. Methods Enzymol. 65:499-560.

22. Meyer, K. B., and M. S. Neuberger. 1989. The immunoglobulin $\kappa$ locus contains a second, stronger B cell-specific enhancer which is located downstream of the contrast region. EMBO J. 8:1959-1964.

23. Murre, C., P. S. McCaw, and D. Baltimore. 1989. A new DNA binding and dimerization motif in immunoglobulin enhancer binding, daughterless, MyoD, and myc proteins. Cell 56:777783.

24. Nelsen, B., T. Kadesch, and R. Sen. 1990. Complex regulation of the immunoglobulin $\mu$ heavy-chain gene enhancer: $\mu B$, a new determinant of enhancer function. Mol. Cell. Biol. 10:31453154.

25. Parslow, T. G., D. L. Blair, W. J. Murphy, and D. K. Granner. 1984. Structure of the $5^{\prime}$-ends of immunoglobulin genes; a novel conserved sequence. Proc. Natl. Acad. Sci. USA 81:2650-2654.

26. Parslow, T. G., S. D. Jones, B. Bond, and K. R. Yamamoto. 1987. The immunoglobulin octanucleotide: independent activity and selective interaction with enhancers. Science 235:14981501.

27. Perez-Mutul, J., M. Macchi, and B. Wasylyk. 1988. Mutational analysis of the contribution of sequence motifs within the $\mathrm{IgH}$ enhancer to tissue specific transcriptional activation. Nucleic Acids Res. 16:6085-6096.

28. Peterson, C. L., and K. L. Calame. 1987. Complex protein binding within the mouse immunoglobulin heavy-chain enhancer. Mol. Cell. Biol. 7:4194-4203.

29. Pierce, J. W., M. Lenardo, and D. Baltimore. 1988. Oligonucleotide that binds nuclear factor NF- $\mathrm{BB}$ acts as a lymphoidspecific and inducible enhancer element. Proc. Natl. Acad. Sci. USA 85:1482-1486.

30. Scheuermann, R. H., and U. Chen. 1989. A developmentalspecific factor binds to repressor sites flanking the immunoglobulin heavy-chain enhancer. Genes Dev. 3:1255-1266.

31. Schlokat, U., D. Bohmannn, H. Schoeler, and P. Gruss. 1986. Nuclear factors binding specific sequences within the immunoglobulin enhancer interact differentially with other enhancer elements. EMBO J. 5:3251-3258.

32. Schoeler, H. R., and P. Gruss. 1984. Specific interaction between enhancer-containing molecules and cellular components. Cell 36:403-411.

33. Schoeler, H. R., A. K. Hatzopoulos, R. Balling, N. Suzuki, and P. Gruss. 1989. A family of octamer-specific proteins present during mouse embryogenesis: evidence for germline-specific expression of an Oct factor. EMBO J. 8:2543-2550.

34. Sen, R., and D. Baltimore. 1986. Multiple nuclear factors interact with the immunoglobulin enhancer sequences. Cell 46:705-716.

35. Sen, R., and D. Baltimore. 1989. Factors regulating immunoglobulin-gene transcription, p. 327-344. In T. Honjo, F. W. Alt, and T. H. Rabbitts (ed.), Immunoglobulin genes. Academic Press, London.

36. Singh, H., R. Sen, D. Baltimore, and P. Sharp. 1986. A nuclear factor that binds a conserved sequence motif in transcriptional control elements of immunoglobulin genes. Nature (London) 319:154-158.

37. Sive, H. L., and R. G. Roeder. 1986. The interaction of a common factor with conserved promoter and enhancer sequences in histone $\mathrm{H} 2 \mathrm{~b}$, immunoglobulin and $\mathrm{U} 2$ small nuclear (sn) RNA genes. Proc. Natl. Acad. Sci. USA 83:6382-6386.

38. Staudt, L. M., R. G. Clerc, H. Singh, J. H. LeBowitz, P. A. Sharp, and D. Baltimore. 1988. Molecular cloning of a lymphoidspecific cDNA encoding a protein that binds to the regulatory octamer DNA motif. Science 241:577-580.

39. Staudt, L. M., H. Singh, R. Sen, T. Wirth, P. A. Sharp, and D. Baltimore. 1986. A lymphoid-specific protein binding to the octamer motif of immunoglobulin genes. Nature (London) 323: 640-643.

40. Stewart, G. S. A. B., S. Dovey, and D. M. O'Rourke. 1988. A rapid method for site directed mutagenesis of plasmid DNA. BioTechniques 6:511-518.

41. Sturm, R. A., G. Das, and W. Herr. 1988. The ubiquitous octamer binding protein Oct-1 contains a Pou domain with a homeo box subdomain. Genes Dev. 2:1582-1599.

42. Tsao, B. P., X.-F. Wang, C. L. Peterson, and K. Calame. 1988. In vivo functional analysis of in vitro protein binding sites in the immunoglobulin heavy chain enhancer. Nucleic Acids Res. 16:3239-3253.

43. Weinberger, J., D. Baltimore, and P. Sharp. 1986. Distinct factors bind to apparently homologous sequences in the immunoglobulin heavy-chain enhancer. Nature (London) 322:846847.

44. Weinberger, J., P. S. Jat, and P. A. Sharp. 1988. Localization of a repressive sequence contributing to B-cell specificity in the immunoglobulin heavy-chain enhancer. Mol. Cell. Biol. 8:988992.

45. Wirth, T., L. Staudt, and D. Baltimore. 1987. An octamer oligonucleotide upstream of a TATA motif is sufficient for lymphoid-specific promoter activity. Nature (London) 329:174 177. 